\title{
Electrochemical Studies of Paracetamoland Folic Acid in the Presence of Epinephrineat Poly (Eosin) Modified Electrode: A Voltammetric Study
}

\section{Kuskur $\mathrm{CM}^{1}$, Kumara Swamy $\mathrm{BE}^{2 *}$ and Jayadevappa $\mathrm{H}^{1}$}

${ }^{1}$ Department of P.G. Studies and Research in Industrial Chemistry, Kuvempu University, JnanaSahyadri, Shankaraghatta, Shimoga, Karnataka 577451, India

${ }^{2}$ Departments of Chemistry, Sahyadri Science College, Shimoga, Karnataka, India

\begin{abstract}
In this work, Poly eosin modified carbon paste electrode was prepared by electropolymerisation method by using cyclic voltammetry technique. This poly (Eosin) modified CPE exhibited an excellent electrocatalytic activity towards the oxidation PA and FA in presence of EP in 0.2M PBS at pH 7.0. The effect of $\mathrm{pH}$ and sweep rate was studied. The limit of detection of PA and FA were found to be 0.06 and $0.04 \mu \mathrm{M}$, respectively. An electrochemical simultaneous separation was observed in a binary mixture containing PA, FA and EP and interference study was done by differential pulse voltammetry technique. Finally, the prepared fabricated sensor exhibits good sensitivity, and selectivity.
\end{abstract}

Keywords: Paracetamol, epinephrine and folic acid; Eosin; Cyclic electrocatalytic activity; Simultaneous determination

\section{Introduction}

Paracetamol or acetaminophen is an analgesic medicament similar to acetylsalicylic acid lacking anticoagulatory properties and gastric irritation. It is widely used as an active ingredient in pharmaceutical preparations as it is not considered to be carcinogenic at therapeutic doses. Paracetamol products give relief for all kinds of mild to moderate pain, including a headache, rheumatic pains, pains from minor injuries and all the everyday aches of normal life [1-3]. Overdose ingestions of Paracetamol lead to accumulation of toxic metabolites, which may cause severe and sometimes fatal hepatotoxicity and nephrotoxicity [45], which in some cases associate with renal failure. Thus, the development of a simple, precise and accurate procedure for the determination of this drug in pharmaceutical products is very useful. Many methods have been so far reported for its determination of paracetamol such as spectrophotometry [6], high performance liquid chromatography [7], and voltammetry [8]. These techniques are generally expensive and time-consuming. There are several number of modified electrodes like titanium oxide nanoparticle $\mathrm{MPE}$, nafion/ $\mathrm{TiO}_{2}$ - graphene modified $\mathrm{GPE}, \mathrm{ZrO}_{2}$ nano particle modified CPE, single walled carbon nanotube.

MCPE have been reported for the determination of acetaminophen by using voltammetric techniques [9-13]. On the other hand, Epinephrine (EP), also called adrenaline, is an important catecholamine neurotransmitter in the mammalian central nervous system [14] which exists as an organic cation in the nervous tissue and biological body fluid. Epinephrine is synthesized naturally in the body from L-tyrosine by the action of different enzymes. Many life phenomena are related to the concentration of EP in blood. It is also served as a chemical mediator for conveying the nerve pulse to different organs. Medically, EP has been used as a common emergency healthcare medicine $[15,16]$. The presence of EP in the body affects the regulation of blood pressure and the heart rate, lipolysis, immune system, and glycogen metabolism. It elevates the blood sugar level by increasing catalysis of glycogen to glucose in the liver, and at the same time begins the breakdown of lipids in fat cells [17]. These important actions of EP also make it a potent doping agent and hence, it is also banned in competitive games by the World Anti-Doping Agency $[18,19]$. Low levels of EP have been found in patients with Parkinson's disease [20-22]. From the point of view of medicine, it is a drug for emergency treatment in severe allergic reaction, cardiac arrest and sepsis [23]. Therefore, the quantitative determination of EP concentration in different human fluids, such as plasma and urine, is important for developing nerve physiology, pharmacological research and life science [24].

FA, N-[p-\{[(2-amino-4-hydroxy-6-pteridinyl) methyl $]$ amino $\}$ benzoyl]-L-glutamic acid, often regarded as a part of vitamin B complex, possesses the considerable biological importance for general human health, especially during periods of rapid cell division and growth $[25,26]$. Deficiency of folic acid is a common cause of anaemia and it is thought to increase the likelihood of heart attack and stroke. Many studies suggest that diminished folate status is associated with enhanced carcinogenesis as folic acid with vitamin $B_{12}$ participates in the nucleotide synthesis, cell division and gene expression [27]. Periconceptual supplementation of folic acid has been demonstrated to reduce significantly the incidence and reoccurrence of neural tube defects, such as spina bifida of women [28]. In January 1998, the US Food and Drug Administration introduced mandatory fortification of cereal grain products with folic acid at a concentration of $140 \mathrm{mg} / 100$ g [29]. In the UK, the Department of Health proposed fortification of flour with folic acid at $240 \mathrm{mg} / 100 \mathrm{~g}$ [30-31].

In the present day's carbon paste electrode was very much attracted towards the determination of biologically active molecules because of the easy preparation of modified electrode, renewability, low background current and fast response. However, Polymer modified electrodes (PMEs) have received great attention in recent years. As the polymer film which is deposited onto the surface of the electrode by electropolymerisation have good stability, reproducibility, more active sites, homogeneity and strong adherence to the electrode surface. Electropolymerisation is a good approach to immobilize polymers to prepare PMEs [13,32-33].

*Corresponding author: Kumara Swamy BE, Departments of Chemistry, Sahyadri Science College, Shimoga, Karnataka, India, Tel: +91-8282-256225 (Off); Fax: +91-8282-256255; E-mail: kumaraswamy21@yahoo.com

Received June 28, 2017; Accepted July 10, 2017; Published July 17, 2017

Citation: Kuskur CM, Kumara Swamy BE, Jayadevappa H (2017) Electrochemical Studies of Paracetamoland Folic Acid in the Presence of Epinephrineat Poly (Eosin) Modified Electrode: A Voltammetric Study. J Biosens Bioelectron 8: 244. doi: 10.4172/2155-6210.1000244

Copyright: (c) 2017 Kuskur CM, et al. This is an open-access article distributed under the terms of the Creative Commons Attribution License, which permits unrestricted use, distribution, and reproduction in any medium, provided the original author and source are credited. 
Citation: Kuskur CM, Kumara Swamy BE, Jayadevappa H (2017) Electrochemical Studies of Paracetamoland Folic Acid in the Presence of Epinephrineat Poly (Eosin) Modified Electrode: A Voltammetric Study. J Biosens Bioelectron 8: 244. doi: 10.4172/2155-6210.1000244

Page 2 of 7

\section{Materials and Methods}

Cyclic voltammetric experiments were performed on a model $\mathrm{CH} 660 \mathrm{c}$ ( $\mathrm{CH}$ instrument). All the electrochemical experiments were carried out in a three-electrode cell system, which contained a bare carbon paste electrode (BCPE)/Poly (Eosin) film coated MCPE as the working electrode, a platinum wire and saturated calomel electrode as the counter and the reference electrode.

\section{Reagents and chemicals}

Epinephrine (EP), Paracetamol (PA), Folic acid (FA), and Eosin was obtained from Himedia. $25 \times 10^{-4} \mathrm{M}$ PA was prepared in double distilled water, $25 \times 10^{-4} \mathrm{M}$ FA was prepared in $0.1 \mathrm{NaOH}$ solution, 25 $\times 10^{-4} \mathrm{M}$ EP was prepared in $0.1 \mathrm{M}$ perchloric acid $\left(\mathrm{HClO}_{4}\right), 25 \times 10^{-4}$ $\mathrm{M}$ Eosin was prepared in double distilled water and Phosphate buffer solution (PBS) of same ionic strength was prepared $(0.2 \mathrm{M})$ by mixing appropriate ratio of sodium dihydrogen phosphate $\left(\mathrm{NaH}_{2} \mathrm{PO}_{4} \cdot \mathrm{H}_{2} \mathrm{O}\right)$ disodium hydrogen phosphate $\left(\mathrm{Na}_{2} \mathrm{HPO}_{4}\right)$. Graphite powder of 50 $\mathrm{mm}$ size was purchased from Loba and silicon oil was purchased from Himedia. All the chemicals are of analytical grade quality and were used as supplied without further purification.

\section{Preparation of barecarbon paste electrode}

Bare carbon paste electrodes (BCPE) were made with silicon oil $(30 \%)$, and graphite powder $(70 \%)$. The two components were thoroughly mixed in an agate mortar for about $30 \mathrm{~min}$. The BCPE was packed into a homemade Teflon cavity having a current collector and was polished on a weighing paper.

\section{Result and Discussion}

\section{Electropolymerisation of eosin at carbon paste electrode}

Polymer film modified carbon paste electrode was fabricated by electropolymerization of eosin at the surface of the CPE by CV method containing in $0.5 \mathrm{mM}$ Eosin in $0.1 \mathrm{M} \mathrm{NaOH}$ solution as supporting electrolyte. Electropolymerization was conducted between the potential windows of $-0.2 \mathrm{~V}$ to $+1.4 \mathrm{~V}$ at the sweep rate of $100 \mathrm{mV} / \mathrm{s}$ for ten cycles. In the process of recording the multiple cycles, the voltammograms was slowly decreased with increasing in cyclic time as shown in Figure 1. Its indicate that, a thin layer of poly (eosin) was deposition on the surface of CPE.

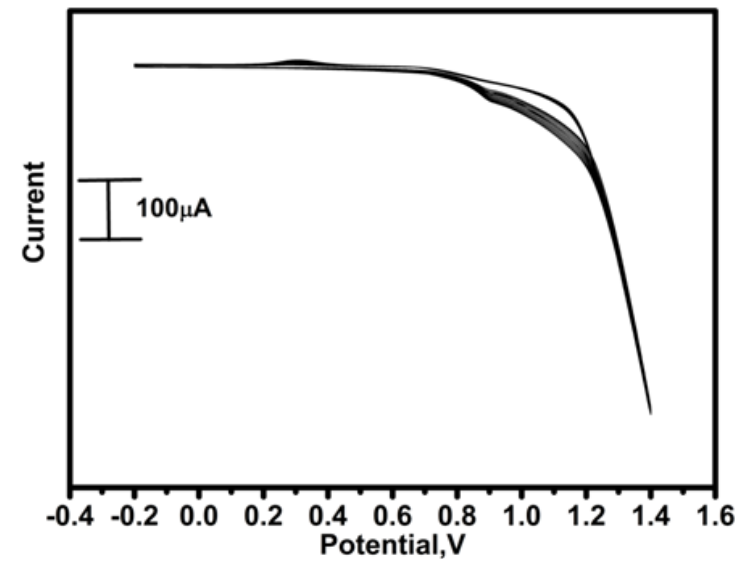

Figure 1: Electropolymerzation of $0.5 \mathrm{mM}$ of Eosin at $0.1 \mathrm{M} \mathrm{NaOH}$ as supporting electrolyte for 10 cycles with the sweep rate of $100 \mathrm{mV} / \mathrm{s}$.

\section{Effect of multiple cycles in the preparation of poly (Eosin)} MCPE

From the above experimental result shows, the thickness of the film has a major contribution on the electrocatalytic property of the poly (Eosin) MCPE. The formation of the layer was controlled by varying the number of cycles on the BCPE (from 5 to 20) and corresponding electrocatalytic activity towards the oxidation of $0.1 \mathrm{mM}$ PA in $0.2 \mathrm{M}$ $\mathrm{PBS}$ of $\mathrm{pH}$ 7.0.The graph of anodic peak current (Ipa) versus the number of cycles was constructed and the graph shows linearly increasing the number of cycles from 5 to 20 as shown in Figure 2. However, a better catalytic performance was observed for the electrode which was modified by 10 consecutive cycle scans [13]. Therefore, ten cycles were selected for the electropolymerization of Eosin as favourable outcome from all the parameters (Figures 1 and 2).

\section{Electrocatalytic reaction of PA at poly (Eosin) modified CPE}

Figure 3 depicts the cyclic voltammetric response for electrochemical oxidation of $0.1 \mathrm{mM}$ PA at bare CPE (dashed line) and poly (Eosin) modified CPE (Solid line) in $0.2 \mathrm{M}$ PBS of $\mathrm{pH} 7$ recorded at a sweep rate of $100 \mathrm{mV} / \mathrm{s}$. At bare CPE, PA shows only oxidation peak was observed and it is an irreversible behaviour. The oxidation peak potential was observed at $408 \mathrm{mV}$. The excellent response is observed at poly (Eosin) modified CPE which shows a well-defined oxidation peak potential at

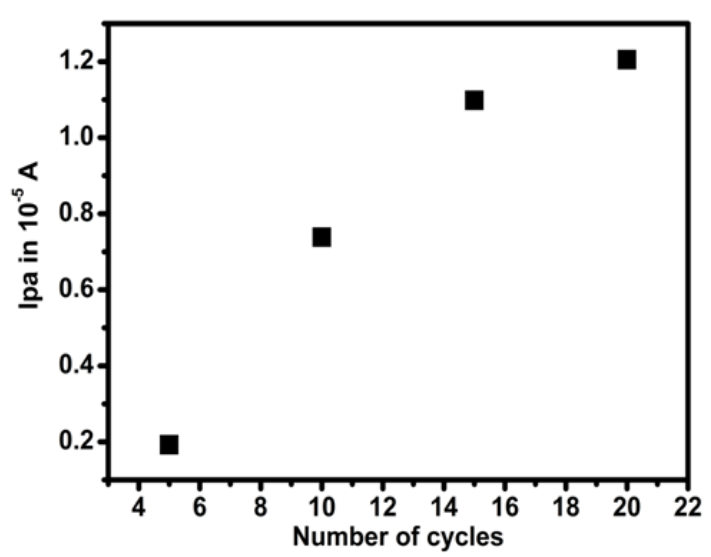

Figure 2: Graph of anodic peak current versus the number of cycles.

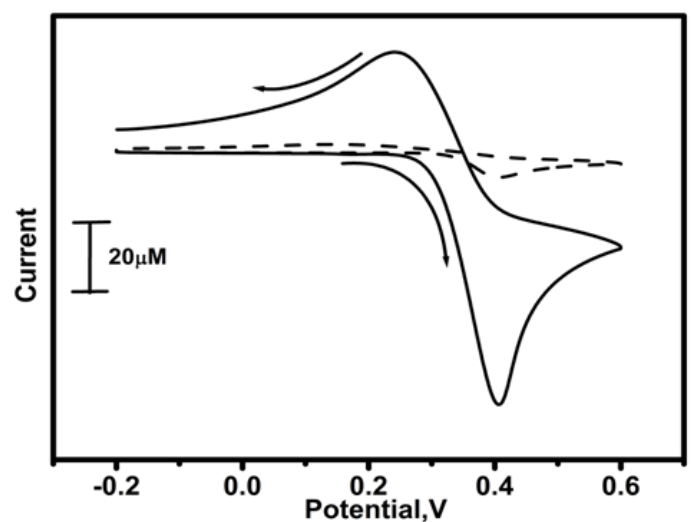

Figure 3: Cyclic voltammograms of $0.1 \mathrm{mM}$ PA in $0.2 \mathrm{M}$ PBS solution of $\mathrm{pH} 7.0$ at BCPE (dashed line) and poly (Eosin) modified CPE (Solid line) at the sweep rate of $100 \mathrm{mV} / \mathrm{s}$. 
Citation: Kuskur CM, Kumara Swamy BE, Jayadevappa H (2017) Electrochemical Studies of Paracetamoland Folic Acid in the Presence of Epinephrineat Poly (Eosin) Modified Electrode: A Voltammetric Study. J Biosens Bioelectron 8: 244. doi: 10.4172/2155-6210.1000244

$406 \mathrm{mV}$ and corresponding reduction peak potential at $242 \mathrm{mV}$ with a significant enhanced in the redox peak current. These results clearly reveal that, poly (Eosin) modified CPE acts as a very efficient promoter to enhance the kinetics of the electrochemical oxidation of paracetamol [34] (Figures 3 and 4).

\section{Effect of PA and FA sweep rate at Poly (Eosin) modified CPE}

The effect of varying sweep rates on the cyclic voltammograms of $0.1 \mathrm{mM}$ paracetamol at poly (Eosin) modified CPE as shown in Figure $5 \mathrm{a}$. Based on a plot the observation shows that increased in the sweep rates the redox peak current also increased within the range from 50 to $400 \mathrm{mV} / \mathrm{s}$. To calculate the electrode process, the graph of Ip versus sweep rates was constructed. The obtained graph was the good linear relationship between the peak currents as shown in Figure 5b. The correlation coefficient value was found to be 0.9997 and 0.9967 , respectively. While at the same time, the graph of Ip versus square root sweep rates were plotted (Figure 5c). Having a correlation coefficient of 0.9935 and 0.9982 , respectively. It indicates that the nature of electrode reaction is adsorption controlled [34-40] (Table 1).

The heterogeneous rate constant $\left(\mathrm{k}^{0}\right)$ values was determined from the experimental peak potential difference $(\Delta \mathrm{Ep})$ data's, eqn. (1) was

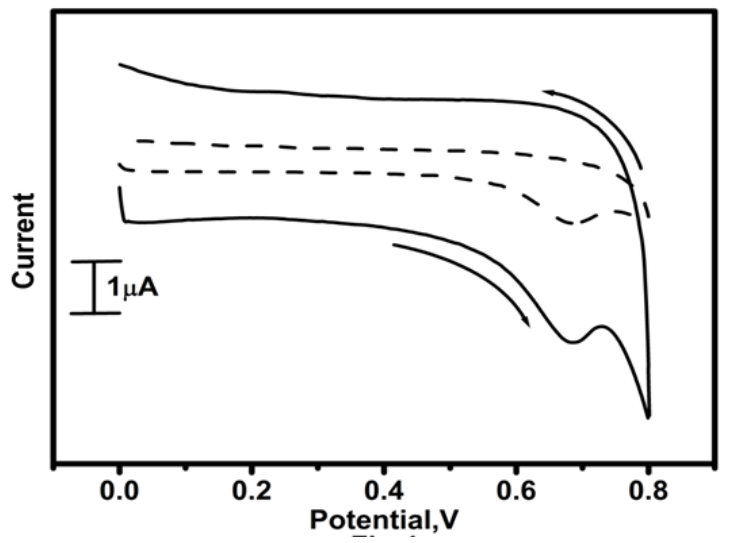

Figure 4: Cyclic voltammograms of $0.1 \mathrm{mM} \mathrm{FA}$ in $0.2 \mathrm{M}$ PBS solution of $\mathrm{pH} 7.0$ at BCPE (dashed line) and poly (Eosin) modified CPE (Solid line) at the sweep rate of $100 \mathrm{mV} / \mathrm{s}$.

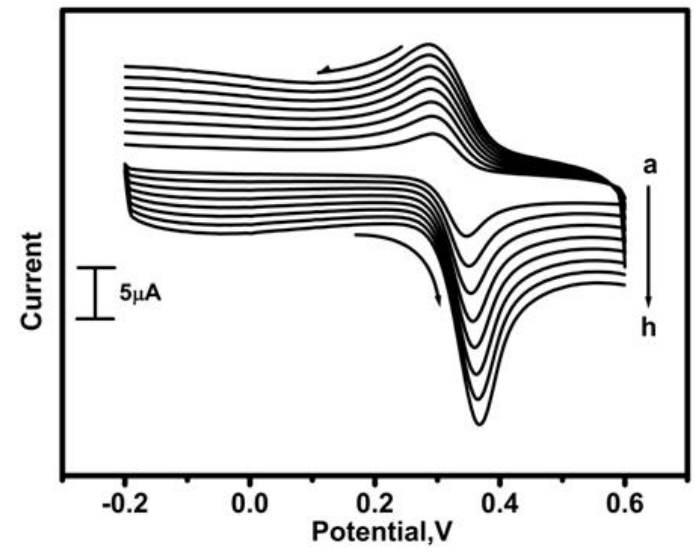

Figure 5a: Cyclic voltammograms of $0.1 \mathrm{mM} \mathrm{PA}$ in $0.2 \mathrm{M}$ PBS solution of $\mathrm{pH}$ 7.0 at Poly (Eosin) modified CPE at different sweep rates (a-h; 50 to $400 \mathrm{mV} / \mathrm{s}$ ).

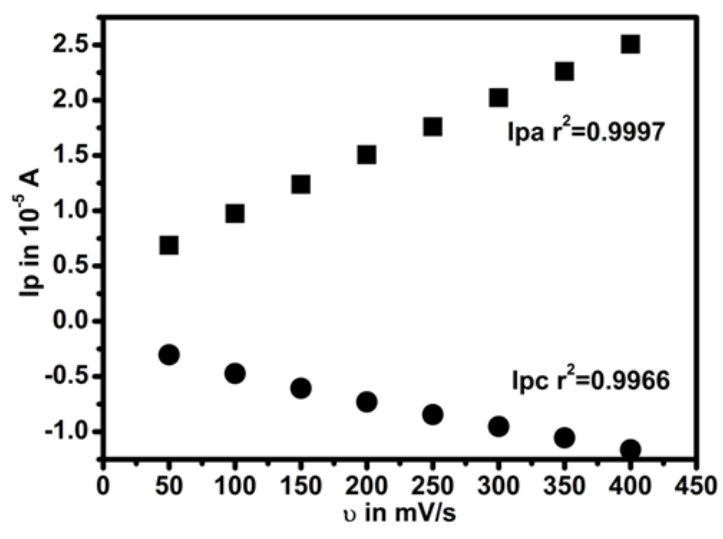

Figure5b: Graph of peak current versus sweep rates.

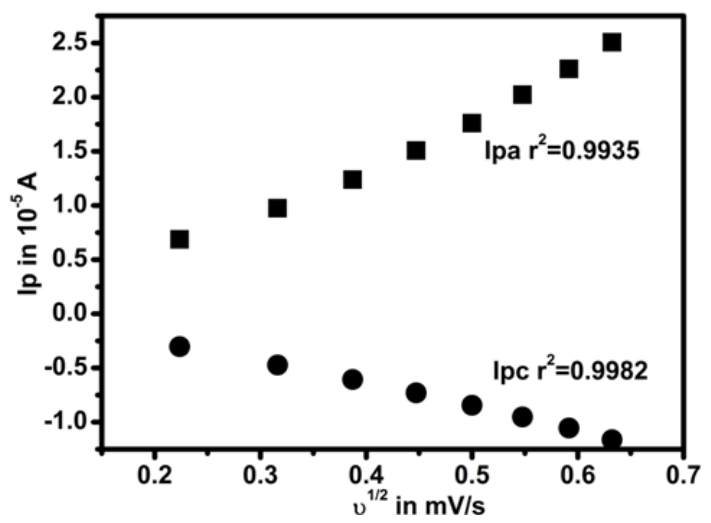

Figure 5c: Graph of peak current versus square root of sweep rates.

\begin{tabular}{|c|c|c|}
\hline vmV/s & $\Delta \mathbf{E p}(\mathbf{V})$ & $\mathbf{k}^{\mathbf{0}}\left(\mathbf{s}^{-1}\right)$ \\
\hline 50 & 55 & 0.8452 \\
\hline 100 & 59 & 1.1618 \\
\hline 150 & 63 & 2.2290 \\
\hline 200 & 67 & 2.9512 \\
\hline 250 & 71 & 3.4673 \\
\hline 300 & 73 & 4.0738 \\
\hline 350 & 80 & 4.3651 \\
\hline 400 & 81 & 5.0350 \\
\hline
\end{tabular}

Table 1: Electrochemical parameters of PA at different sweep rates.

used for such voltammograms whose $\Delta \mathrm{Ep}$ values are greater than 10 $\mathrm{mV}[42-49]$

$$
\Delta \mathrm{Ep}=201.39 \log \left(\mathrm{v} / \mathrm{k}^{0}\right)-301.78
$$

From the experimental $\Delta \mathrm{Ep}$ values as shown in Table 1 and eqn. (1); the values of the $\mathrm{k}^{0}$ for the PA oxidation was determined. All the parameters are tabulated in Table 1.

\section{Effect of PA and FA sweep rate at Poly (Eosin) modified CPE}

The effect of sweep rate on the anodic peak current of 0.1M FA at poly (Eosin) modified CPE was studied by cyclic voltammetry. Figure 6a shows an increase in the anodic peak current by increasing the sweep rate from 100 to $450 \mathrm{mV} / \mathrm{s}$. Figure $6 \mathrm{~b}$ shows the plot of the Ipa versus the sweep rates shows almost straight line with a good linearity as shown having correlation co-efficient 0.9980 . It indicates that 
Citation: Kuskur CM, Kumara Swamy BE, Jayadevappa H (2017) Electrochemical Studies of Paracetamoland Folic Acid in the Presence of Epinephrineat Poly (Eosin) Modified Electrode: A Voltammetric Study. J Biosens Bioelectron 8: 244. doi: 10.4172/2155-6210.1000244

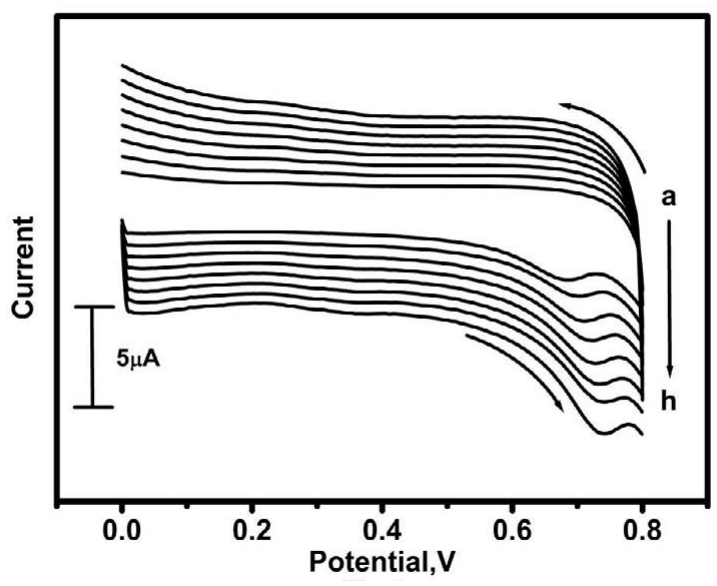

Figure 6a: Cyclic voltammograms of $0.1 \mathrm{mM} F A$ in $0.2 \mathrm{M}$ PBS solution of $\mathrm{pH}$ 7.0 at Poly (Eosin) modified CPE at different sweep rates (a-h; 100 to 450 $\mathrm{mV} / \mathrm{s})$.

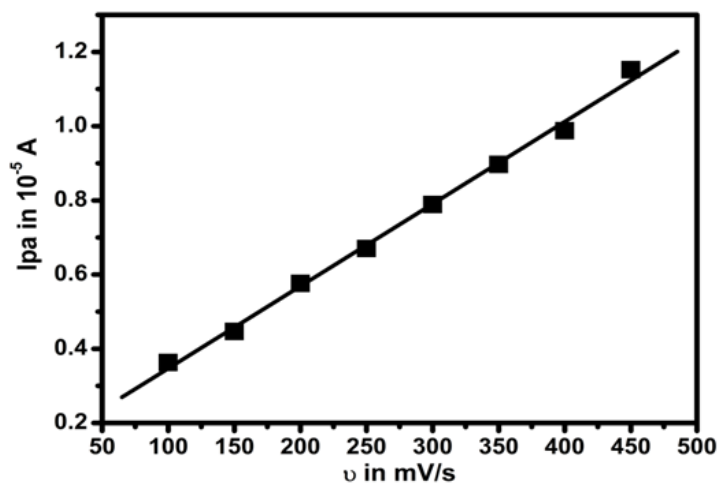

Figure 6b: Graph of peak current versus sweep rates.

irreversible oxidation process of FA at the poly (Eosin) modified CPE was adsorption controlled electrode reactions [37].

\section{Effect of PA and FA concentration at Poly (Eosin) modified CPE}

The electrocatalytic oxidation of PA was carried out by varying its concentration at poly (Eosin) modified CPE. Figure 7a depicts the cyclic voltammograms of various concentrations of paracetamol $(0.1$ to $0.7 \mathrm{mM}$ ). By increasing the concentration of PA, the electrochemical redox peak current goes on increasing. The graph of Ipa versus concentration of PA was constructed as shown in Figure $7 \mathrm{~b}$. The correlation coefficient value was found to be 0.9954 .The limit of detection of PA is $0.06 \mu \mathrm{M}$ and in the same time Figure $8 \mathrm{a}$ indicates that the cyclic voltammograms of successive improvement of peak current on increasing concentration of PA. The graph of anodic peak current peak current versus the concentration of PA from the range of 0.1 to $0.5 \mathrm{mM}$. The obtained graph has good linearity and almost straight line as shown in Figure $8 \mathrm{~b}$ having a correlation coefficient of 0.9964 . The limit of detection was calculated [38] and it was found to be 0.06 $\mu \mathrm{M}[\mathrm{PA}]$ and $0.04 \mu \mathrm{M}[\mathrm{FA}]$, respectively. The performance of modified electrode exhibited lower detection limit than other reported and given it in the Tables 2 and 3.

$\mathrm{LOD}=3 \mathrm{~S} / \mathrm{M}$

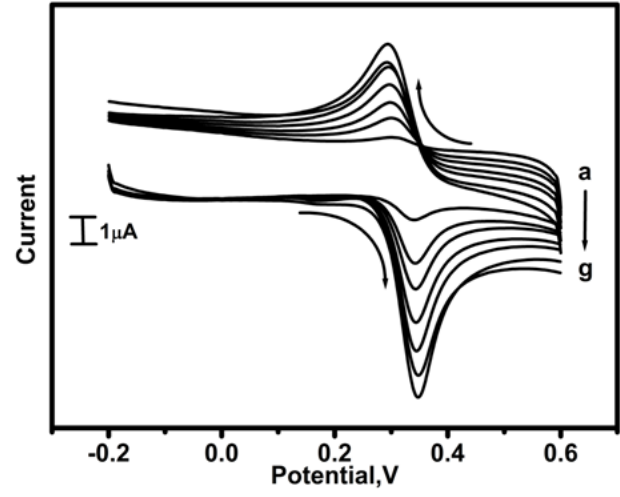

Figure 7a: Cyclic voltammograms of PA in $0.2 \mathrm{M} \mathrm{PBS}$ solution of $\mathrm{pH} 7.0$ at poly (Eosin ) modified CPE at sweep rate of $100 \mathrm{mV} / \mathrm{s}$ with different concentrations (a-g:0.1 mM, 0.2 mM,0.3 mM, 0.4 mM, 0.5 mM, 0.6 mM and 0.7 mM).

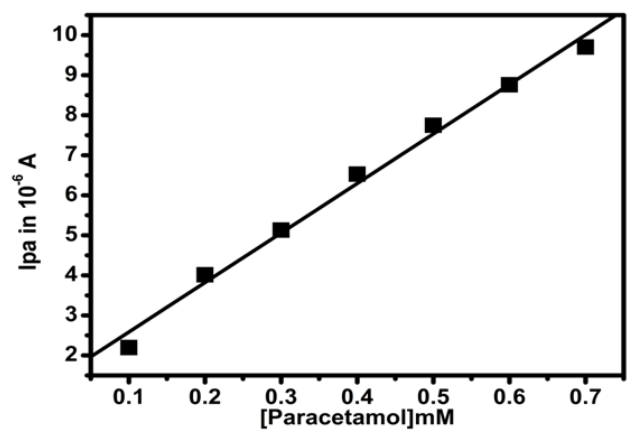

Figure 7b: Graph of anodic peak current versus concentration of PA.

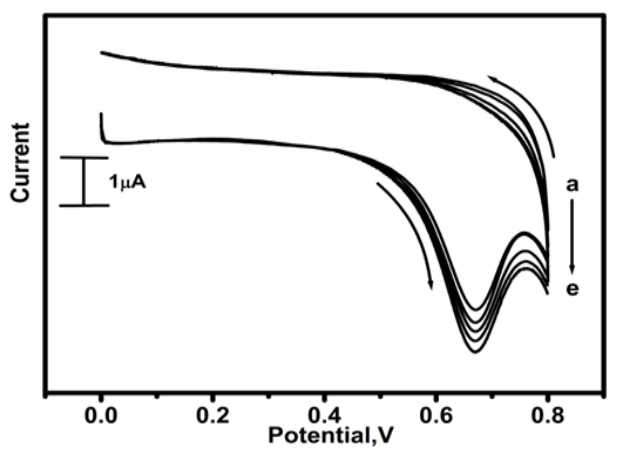

Figure 8a: Cyclic voltammograms of FA in $0.2 \mathrm{M} \mathrm{PBS}$ solution of $\mathrm{pH} 7.0$ at poly (Eosin ) modified CPE at sweep rate of $100 \mathrm{mV} / \mathrm{s}$ with different concentrations (a-e:0.1 mM, 0.2 mM, 0.3 mM, 0.4 mM, and 0.5 mM).

Where $S$ is standard deviation and $M$ is the slope.

PA, FA and EP electrochemical determination by Simultaneous method

The main aim is the simultaneous determination of PA, FA and EP in a $0.2 \mathrm{M}$ phosphate buffer solution of $\mathrm{pH} 7$ at poly (Eosin) modified CPE. Figure 9 shows the simultaneous determination of PA, EP and FA by poly (Eosin) MCPE and BCPE in a mixture of solution. As can be seen the BCPE, there is failed to separate the voltammogram in the backward scan is indistinguishable but oxidation takes place only (solid line), however, in the same condition poly (Eosin) MCPE 
Citation: Kuskur CM, Kumara Swamy BE, Jayadevappa H (2017) Electrochemical Studies of Paracetamoland Folic Acid in the Presence of Epinephrineat Poly (Eosin) Modified Electrode: A Voltammetric Study. J Biosens Bioelectron 8: 244. doi: 10.4172/2155-6210.1000244

Page 5 of 7

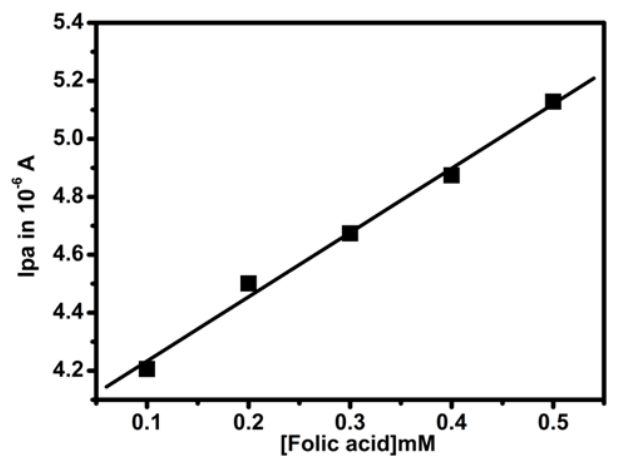

Figure 8b: Graph of anodic peak current versus concentration of FA.

\begin{tabular}{|l|l|c|c|c|}
\hline S. No & Electrode & $\begin{array}{l}\text { Detection } \\
\text { limit }(\boldsymbol{\mu M} \mathbf{M})\end{array}$ & Techniques & Reference \\
\hline $\mathbf{1}$ & SPE/PEDOT & 1.39 & DPV & 43 \\
\hline 2 & Nafion/ROPCME/GCE & 1.2 & SWV & 44 \\
\hline 3 & BDDE & 0.81 & DPV & 45 \\
\hline 4 & GCE/f-MWCNT & 0.6 & DPV & 46 \\
\hline 5 & Poly (Eosin) modified CPE & 0.06 & CV & Present work \\
\hline
\end{tabular}

Table 2: Comparison of some modified electrodes for determination of PA.

\begin{tabular}{|l|l|c|c|c|}
\hline S. No & Modified Electrode & $\begin{array}{c}\text { Detection } \\
\text { limit }(\boldsymbol{\mu M})\end{array}$ & Techniques & Reference \\
\hline 1 & $\mathrm{ZrO}_{2}$ nanoparticles & $9.86 \times 10^{-6}$ & DPV & 47 \\
\hline 2 & $\mathrm{BH}^{\mathrm{d}} \& \mathrm{TiO}_{2}$ nanoparticles & $2.5 \times 10^{-5}$ & $\mathrm{DPV}$ & 48 \\
\hline 3 & $\mathrm{SAOSMCPE}^{-5}$ & $2.88 \times 10^{-5}$ & $\mathrm{CV}$ & 49 \\
\hline 4 & $\mathrm{PANI} / \mathrm{TPA}$ & $3.0 \times 10^{-7}$ & $\mathrm{DPV}$ & 50 \\
\hline 5 & Poly (Eosin) modified CPE & 0.04 & $\mathrm{CV}$ & Present work \\
\hline
\end{tabular}

Table 3: Comparison of some modified electrodes for determination of FA

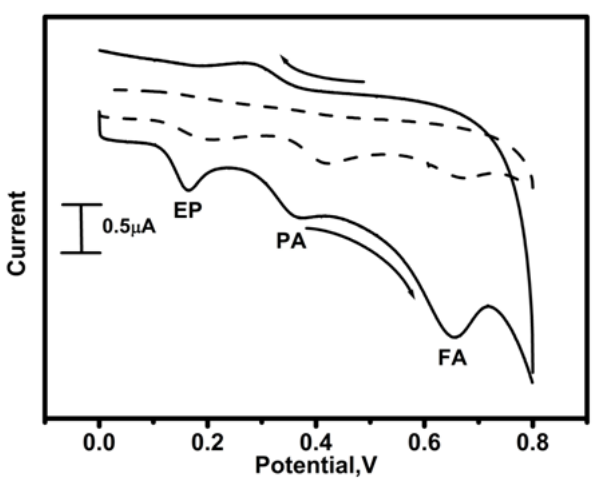

Figure 9: Cyclic voltammograms for simultaneous determination of $0.1 \mathrm{mM}$ PA, 0.1 mM FA at BCPE (dashed line) and poly (Eosin) modified CPE (solid line) at sweep rate of $100 \mathrm{mV} / \mathrm{s}$

can separate the overlapped cyclic voltammogram, among three electroactive species PA shows reduction takes place in the reverse scan (dashed line). Also the peak current of oxidation of these three substances significantly increases at the poly (Eosin) MCPE [40].

\section{Interference}

The differential pulse voltammetric technique was used for simultaneous determination because of its more sensitivity and selectivity with negligible background current [40]. In this study, by altering the concentration of one analyte while the other two analytes were kept constant and vice versa. The concentration PA was varied from 0.1 to $0.6 \mathrm{mM}$ while other two species concentration of EP was 0.1 $\mathrm{mM}$ and FA was $0.1 \mathrm{mM}$ was kept constant (Figure 10).

Similarly in Figures 11 and 12 explain the concentration effect of EP from 0.1 to $0.4 \mathrm{mM}$ and FA from 0.1 to $0.5 \mathrm{mM}$ respectively. This result shows that the oxidation of PA, FA and EP is autonomous to each other. By this method three voltammetric peaks can be separated.

\section{Conclusion}

In conclusion, the poly (Eosin) modified CPE was fabricated by

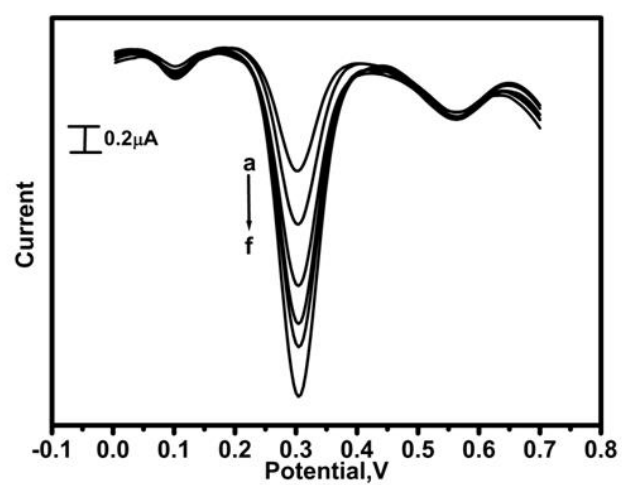

Figure 10: Differential pulse voltammograms of (a) $0.1 \mathrm{mM}$ (b) $0.2 \mathrm{mM}$, (c) 0.3 $\mathrm{mM}$, (d) $0.4 \mathrm{mM},(\mathrm{e}) 0.5 \mathrm{mM}$ and (f) $0.6 \mathrm{mM}$ PA in $0.2 \mathrm{M}$ PBS of pH 7.0 in the presence of $0.1 \mathrm{mM}$ FA and $0.1 \mathrm{mM}$ EP at poly (Eosin) modified CPE .

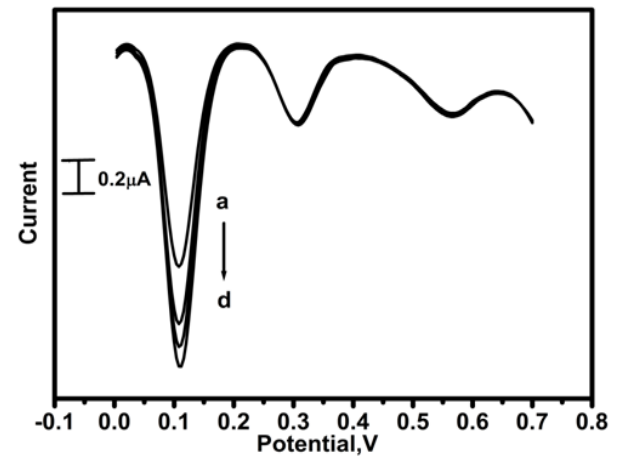

Figure 11: Differential pulse voltammograms of (a) $0.1 \mathrm{mM}$ (b) $0.2 \mathrm{mM}$, (c) 0.3 $\mathrm{mM}$ and (d) $0.4 \mathrm{mM} \mathrm{EP}$ in $0.2 \mathrm{M}$ PBS of $\mathrm{pH} 7.0$ in the presence of $0.1 \mathrm{mM}$ PA and $0.1 \mathrm{mM}$ FA at poly (Eosin) modified CPE

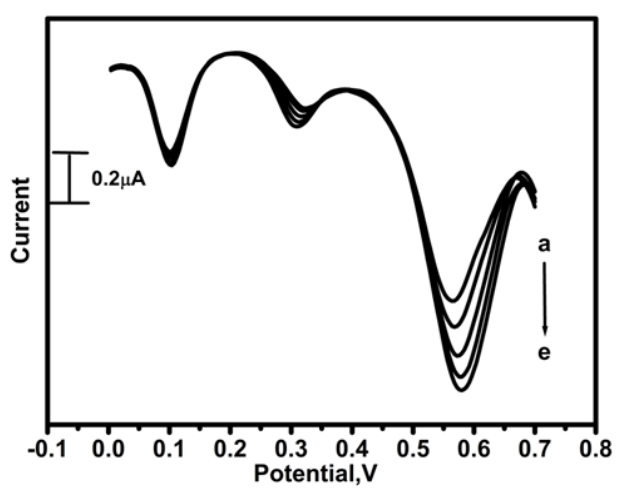

Figure 12: Differential pulse voltammograms of (a) $0.1 \mathrm{mM}$ (b) $0.2 \mathrm{mM}$, (c) 0.3 $\mathrm{mM}$ (d) $0.4 \mathrm{mM}$ and (e) $0.5 \mathrm{mM} \mathrm{FA}$ in $0.2 \mathrm{M}$ PBS of $\mathrm{pH} 7.0$ in the presence of $0.1 \mathrm{mM}$ PA and $0.1 \mathrm{mM}$ EP at poly (Eosin) modified CPE . 
Citation: Kuskur CM, Kumara Swamy BE, Jayadevappa H (2017) Electrochemical Studies of Paracetamoland Folic Acid in the Presence of Epinephrineat Poly (Eosin) Modified Electrode: A Voltammetric Study. J Biosens Bioelectron 8: 244. doi: 10.4172/2155-6210.1000244

Page 6 of 7

using CV technique. The poly (Eosin) modified CPE exhibits highly selectivity and electrocatalytic activity to PA, FA in the presence of EP. This method clearly separated the overlapped peaks into well separated individual peaks. Hence, it is good selectivity and sensitivity, it is expected that poly (Eosin) MCPE could hold great application in the fields of electro analytical chemistry and biosensors.

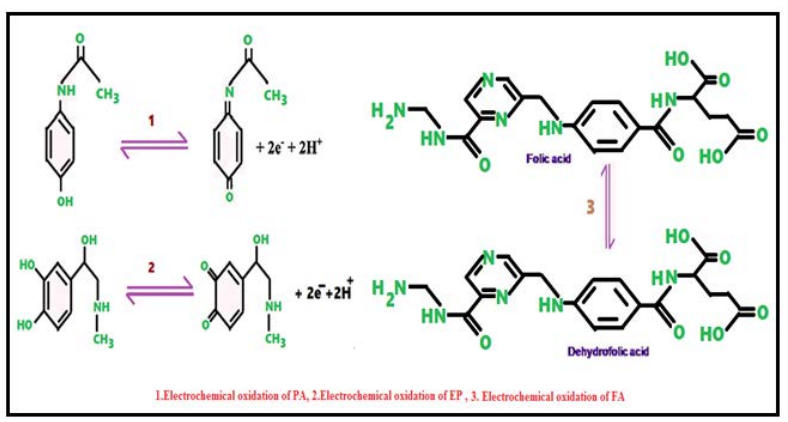

\section{References}

1. Lipton RB, Bigal ME, Kolodner KB, Gorelick PB, Wilks K et al. (2004) Acetaminophen in the treatment of headaches associated with dipyridamoleaspirin combination. Neurlogy 63: 1099-1101.

2. Michel AD, Walter DS (2009) Combination of pyrozolylp27madulaters with further therapeutic PCT Int. Appl.

3. Goyal RN, Gupta VK, Chatterjee S (2010) Voltammetric biosensors for the determination of paracetamol at carbon nanotube modified pyrolytic graphite electrode, Sens. Actuators B 149: 252

4. Mazer M, Perrone J (2008) Acetaminophen-Induced Nephrotoxicity: Pathophysiology, Clinical Manifestations, and Management. Journal of Medical Toxicology 4: 2.

5. Jeevagan J, Abraham John S(2012) Electrochimica Acta 77: 137-142.

6. Khoshayand MR, Abdollahi H, Shariatpanahi M, Saadatfard A, Mohammad A (2008) Simultaneous spectrophotometric determination of paracetamol, ibuprofen and caffeine in pharmacaueticals by chemometric methods. Spectrochim Acta Part A 70: 49-499.

7. Ing-Lorenzini KR, Desmeules JA, Besson M, Veuthey JL, Dayer $\mathrm{P}$, et al (2009) Two-dimentional liquid chromatography ion-trap mass spectrometry for the simultaneous determination of ketorolac enantiomers and paracetamol in human plasma: Application to a pharmacokinetic study. J Chromatog A 1216: 3851-3856.

8. Burgot G, Auffret F, Burgot JL (1997) Determination of acetaminophen by thermometric titrimetry. Ana ChimActa 343: 125-128.

9. Gururaj KJ, Swamy BEK (2013) Electrochemical Synthesis of Titanium Nano Particles at Carbon Paste Electrodes and Its Applications as an Electrochemical Sensor for the Determination of Acetaminophen in Paracetamol Tablet. Soft Nanoscience Letter 3: 20-22.

10. Mohammad MA, Hadi B, Mohammad KA, Fakhradin M, Mohammad A (2010) New strategy for simultaneous and selective voltammetric determination of norepinephrine, acetaminophen and folic acid using $\mathrm{ZrO}_{2}$ nanoparticles modified carbon paste electrode. Sens Actuators B 151: 243-249.

11. Biuck H, Mojtaba J, Mohammad HPA (2011) Differential pulse voltammetric simultaneous determination of acetaminophen and ascorbic acid using single-walled carbon nanotube-modified carbon-ceramic electrode. J Anal Biochemistry 411: 167-175

12. Yang F, Jin HL, Hai TL, Qin Z (2011) Electrochemical behaviour andvoltammetric determination of paracetamol on Nafion/TiO2-graphene modified glassy carbon electrode. Colloids Surf B: Biointerfaces 85: 289-292.

13. Harisha KV, Swamy BEK, Jayadevappa H, Ganesh PS (2016) Electrochemical Sensor for the Determination of Adrenaline in Presence of Acetaminophen at Poly (Alanine) Modified Carbon Paste Electrode: A Cyclic Voltammetric Study. $\mathrm{J}$ Biosens Bioelectron 7:4.

14. Hernandez P, Sanchez O, Paton F (1998) Cyclic voltammetry determination of epinephrine with a carbon fiber ultramicroelectrode. Talanta 46: 985.
15. Deftereos TN, Calokerinos AC, Efstathiou CE (1993) Analyst 118: 627.

16. Gholivand MB, Yawari E (2012) A graphene-based electrochemical sensor for simultaneous determination of epinephrine and uric acid.chemical sensors 2: 11 .

17. Clark MG, Colquhoun EQ, Rattigan S, Dora KA, Eldershaw TP, et al. (1995) American Journal of Physiology, Endocrinology and Metabolism 268:797.

18. Substance classification booklet, Canadian Centre for Ethics in Sport (2008).

19. Prohibited Substances and Prohibited Methods of Doping, USADA (2006).

20. Hsu CW, Yang MC (2008) Isolating cells from blood using buoyancy activated cell sorting (BACS) with glass microbubbles 14th International Conference on Miniaturized Systems for Chemistry and Life Sciences 2010. Sensors and Actuators B: Chemical 134: 680.

21. Silva LIB, Ferreira FDP, Freitas AC, Rocha-Santos TAP, Duarteb AC (2009) Talanta 80: 853.

22. Kalimuthu P, Abraham S (2009) Simultaneous determination of epinephrine, uric acid and xanthine in the presence of ascorbic acid using an ultrathin polymer film of 5-amino-1,3,4-thiadiazole-2-thiol modified electrode. AnalyticaChimicaActa 647: 97.

23. Amorim CG, Araujo AN, Montenegro MCBSM (2007) SI lab-on-valve analysis of histamine using potentiometric detection for food quality control. Talanta 72 1255.

24. Yang Z, Hu G, Chen X, Zhao J, Zhao G (2007) Colloids and Surfaces B 54: 230.

25. Guo HX, Li YQ, Fan LF, Wu XQ, Guo MD (2006)Voltammetric Determination of Folic Acid with a OveroxidizedPolypyrrole Film Modified Sol-Gel Carbon Ceramic Electrode Electrochim Acta 51: 6230-6237.

26. Yang H, Lu B, Qi B, Guo L (2011) Voltammetric sensor based on ordered mesoporous carbon for folic acid determination. Journal of Electroanalytical Chemistry 660: 2-7.

27. Hoegger D, Morier P, Vollet C, Heini D, Reymond F, et al. (2007) Disposable microfluidic ELISA for the rapid determination of folic acid content in food products. Anal Bioanal Chem 387: 267-275

28. Gujska E, Kuncewicz A (2005) Determination of folate in some cereals and commercial cereal-grain products consumed in Poland using trienzyme extraction and high-performance liquid chromatography methods. Eur. Food Res Technol 221: 208-213

29. Food and Drug Administration, Food standards: amendment of standards of identity for enriched grain products to require addition of folic acid, vol. 61. Food and Drug Administration, Rockville, MD, 1996, pp. 8781-8797.

30. Wright AJA, Finglas PM, Southon S (2001) Proposed mandatory fortification of the UK diet with folic acid: have potential risks been underestimated. Trends FoodSci 12: 313-321.

31. Xiao F, Ruan C, Liu L, Yan R, Zhao F, et al. (2008) Single-walled carbon nanotube-ionic liquid paste electrode for the sensitivevoltammetric determination of folic acid. Sensors and Actuators B 134: 895-901.

32. RaneRF, Blaha CD (1990) Detection of catecholamines in brain tissue: surface modified electrodes enabling in vivo investigations of dopamine function. Langmuir 6: 56-65

33. Ewing AG, Dayton MA, Wightman RM (1981) Pulse Voltammetry withMicrovoltammetric Electrodes. J Anal Chem 53: 1842-1847.

34. Massaroppi MRC, Machado SAS, Avaca LA (2003) Electroanalytical Determination of the Herbicide Picloram in Natural Waters by Square Wave Voltammetry. J Braz Chem Soc 14: 113-119.

35. Komorsky-Lovric S, Gagic S, Penovski R (1999) Anal Chim Acta 389:219-223.

36. Quentel F, Elleouet C (2001) Electroanalysis 13: 1030-1035.

37. Sunil Kumar Naik TS, Kumara Swamy BE, Vishwanath CC, Kumar M (2015) Electrochemical Determination of Folic Acid at Sodium Alpha Olefin Sulphonate Modified Carbon Paste Electrode: A Voltammetric Study. J Anal Bioanal Tech 6: 272.

38. Kuskur CM, Swamy BEK, Jayadevappa H (2015) Electrochemical Investigation of Paracetamol at Poly(Glycine) Modified Carbon Paste Electrode: A Voltametric Study. J Anal Bioanal Tech 6: 26.

39. Mazloum-Ardakani M, Sheikh-Mohseni MA, Abdollahi-Alibeik MD, Benvidi A (2012) Sensors and Actuators B. 380-386. 
Citation: Kuskur CM, Kumara Swamy BE, Jayadevappa H (2017) Electrochemical Studies of Paracetamoland Folic Acid in the Presence of Epinephrineat Poly (Eosin) Modified Electrode: A Voltammetric Study. J Biosens Bioelectron 8: 244. doi: 10.4172/2155-6210.1000244

40. Tanuja SB, Kumara Swamy BE, VasantakumarPai K (2017) Electrochemical determination of paracetamol in presence of folic acid at nevirapine modified carbon paste electrode: A cyclic voltammetric study.Journal of Electroanalytical Chemistry 798: 17-23.

41. Reddy S, Swamy BEK, Jayadevappa H (2012)CuO nanoparticle sensor for the electrochemical determination of dopamine. Electrochem. Acta 61: 78-86.

42. SuWY, Cheng SH (2010) Electrochemical Oxidation and Sensitive Determination of Acetaminophen in Pharmaceuticals at Poly(3,4-ethylenedioxythiophene)Modified Screen-Printed Electrodes. Electroanalysis 22: 707-714.

43. Zen JM, Ting YS, Zen JM, Ting YS (1997) Simultaneous determination of caffeine and acetaminophen in drug formulations by square-wave voltammetry using a chemically-modified electrode. AnalyticaChimicaActa 342:175-180.

44. Radovan C, Cofan C, Cinghita D (2008) Simultaneous Determination of Acetaminophen and Ascorbic Acid at an Unmodified Boron-Doped Diamond
Electrode by Differential Pulse Voltammetry in Buffered Media. Electroanalysis 20: $1346-1353$.

45. Alothman ZA, Bukhari N, Wabaidur SM, Haider S (2010) Simultaneous electrochemical determination of dopamine and acetaminophen using multiwall carbon nanotubes modified glassy carbon electrode. Sensors and Actuators B 146: 314-320.

46. Mazloum-Ardakani M, Beitollahi H, Amini MK, Mirkhalaf F, Abdollahi-Alibeik M (2010) Sensors and Actuators B: Chemical 151: 243-249.

47. Hong Y, Yuanyuan S, Xinhua L, Yuhai T, Liying H (2007) Electrochim Acta 52: 6165.

48. Mazloum-Ardakani M,Beitollahi $H$, Sheikh-Mohseni MA,Naeimi $H$, Taghavinia N (2010) Applied Catalysis A: General 378: 195-201.

49. Mazloum-Ardakani MD, Ali Sheikh-Mohseni MD, Abdollahi-Alibeik MD (2013) Journal of Molecular Liquids 178: 63-69. 